\title{
Collaborations between academic psychiatry and the pharmaceutical industry: A perspective from industry
}

\author{
MAURICIO TOHEN
}

\begin{abstract}
The author offers a perspective on the perceived conflicts of interest that influence scientific collaborations between academic psychiatry and the pharmaceutical industry. The author holds the position that the merits of a particular study should be judged based on the quality of the scientific methodology rather than on the credentials of the investigators or the source of funding.
\end{abstract}

In recent years, there has been an increasing concern regarding conflicts of interest in medical research that question the relationship between academia and the pharmaceutical industry. New guidelines include the disclosure of funding source and in some cases even the exclusion of financial links between an academic investigator and the pharmaceutical company whose products are being studied. The latter suggests that scientific work originating from or supported by industry should not be considered trustworthy.

An extreme view is to dismiss any research that receives industry funding or is conducted by an industry scientist. As noted in a commentary by Rothman (1991), acceptance of this view effectively presupposes that any investigator who works as an industry scientist or collaborates in industry research is committing fraud and/or is incompetent. Implicit in this view is the accusation that any investigator involved in industry funded research deliberately favors the product of the sponsor or employer regardless of the scientific data, and is therefore committing fraud. Furthermore, this view implies that the investigator is incompetent and therefore incapable of designing studies that avoid any type of non-intentional bias. As Rothman (1991) extreme view would discredit and discourage past and future research in collaboration with industry. Being a scientist

\footnotetext{
Address for correspondence: Dr. M. Tohen, Lilly Corporate Center, Indianapolis IN 26285 (USA).

Fax: +1-317-276-7845

E-mail: m.tohen@lilly.com

Declaration of Interest: The author is a full-time employee and a stockholder of Eli Lilly and Company. Dr Tohen is soley responsible for the content of this commentary and it should not be considered as an official position of Eli Lilly and Company.
}

and working with industry would be mutually incompatible.

In scientific research we employ methodology to limit the risk of bias regardless of funding affiliations. Random assignment is instituted to prevent the deliberate allocation of subjects of investigation who are likely to respond to a specific treatment. Blinding of both the subjects of investigation and the raters prevents observation bias. By blinding raters to treatment assignment, bias is avoided even if they unconsciously want to please the sponsor. Rothman (1991) has proposed that the value of the results should not be tainted by affiliation or source of funding, but rather on the strengths of the methodology. If in judging the value of a study an observer is influenced by affiliation or source of funding, notwithstanding the scientific merits, then this is a form of prejudice- similar to prejudice based on ethnicity, gender, degree of physical attractiveness, or sexual preference. I would argue that the best solution to avoiding bias in industry funded research is to focus on improving and implementing research methodology to avoid such bias.

In many instances if the results favor the product of the funding source, readers may be inclined to attribute the findings as a conflict of interest. The results are then dismissed as being merely a product of conflict of interest. This prejudicial approach may lead to the discrediting of potentially valuable scientific findings, ultimately to the detriment of patients.

The passage in the United States of the Bayh-Dole Act in 1980 encouraged the collaboration between academia and industry. The law enabled universities to retain the patent of inventions and encouraged collaborations with for-profit institutions. The act was approved by congress in order to increase the pace of drug development through partnership between industry and academia. The overall goal of the act was to shorten the time to get better phar- 
macological treatments to patients. The vision of the act was that patients would benefit from the closer collaboration between industry and academia. The Dec. 12, 2002, edition of The Economist described the BayhDoyle act as an important step in the development of better pharmaceutical products for patients.

I would argue that Financial Conflicts of Interest are not the sole source of conflict that investigators have when conducting clinical research. The results of a clinical trial will no doubt have an effect on the professional career of clinical investigators as federal or private grants are more likely to be awarded to those with a successful track record. No doubt clinical income and professional success will be determined by a long record of successful publications. There are of course instances where scientific misconduct may be solely ego-driven, rather than financially motivated.

I hold the position that the merits of a particular study be based on the rigor of the scientific methodology rather than on the credentials or affiliations of the investigators. Should a different standard be set depending on the investigators' affiliations? Who then would determine the "correct" hierarchy of affiliation excellence? I therefore argue that the evaluation of scientific publications be judged only on the basis of their scientific merit and be set free of bias or prejudice.

Editors and editorial boards of major psychiatric journals have addressed the topic of conflicts of interest. Lewis et al. (2006) have suggested that "The collaboration between industry and academia is a useful part of the activity of many clinical investigators that enlists our best minds in the development of new therapeutics for our patients". Freedman et al. (2006) also have suggested that "Complete separation from the pharmaceutical industry is not the answer." The authors also emphasized that it is not clear what constitutes an appropriate interaction between industry and academia underlining that "we do not have a consensus for what constitutes good behavior - we are vulnerable to those who criticize our profession for any form of relationship with the pharmaceutical industry".

As suggested by Freedman et al. (2006) academia and the pharmaceutical industry need to set their ethical boundaries and standards. No doubt, in order to establish the "appropriate boundaries", industry and academia need to develop them jointly under the auspices of global scientific organizations such as the World Psychiatric Association.

To summarize, collaborations between industry and academia are no doubt in the best interest of patients. The ethical delimitation of the relationship needs to be jointly developed by scientists from academia and industry.

\section{REFERENCES}

Freedman R., Lewis D.A., Michels R., Pine D.S., Schultz S.K., Tamminga C.A., Patterson S.L., Mcintyre J.S., Goldman H.H., Yudofsky S.C., Hales R.E., Rapaport M.H., Hales D., Krajeski J., Kupfer D.J., Badaracco M.A. \& Scully J.H. (2006). Conflict of Interest, Round 2. American Journal of Psychiatry 163, 1481-1483.

Lewis D.A., Michels R., Pine D.S., Schultz S.K., Tamminga C.A. \& Freedman R. (2006). Conflict of Interest. American Journal of Psychiatry 163, 571-573.

Rothman K.J. (1991). The Ethics of Research Sponsorship. Journal of Clinical Epidemiology 44, Suppl. 1, 25-28S. 